\title{
Article
}

\section{Adsorption Behaviors of Bioactive Amines and Proteins on Phosphorylated Bacterial Cellulose}

\author{
*Tatsuya Oshima, Sachiko Taguchi, Hiromi Fujiwara, Kaoru Ohe, and Yoshinari Baba \\ Department of Applied Chemistry, Faculty of Engineering, University of Miyazaki, 1-1, Gakuen Kibanadai Nishi, \\ Miyazaki, 889-2192, Japan
}

(Manuscript submitted March 29, 2007; accepted June 13, 2007)

\begin{abstract}
The present study examined the adsorption of bioactive amines and proteins onto phosphorylated bacterial cellulose (PBC) and phosphorylated plant cellulose (PPC), which contain similar amounts of phosphoric acid groups. Physiologically important organic amines such as dopamine and serotonin are adsorbed onto $\mathrm{PBC}$ at neutral $\mathrm{pH}$. In addition, a cationic protein lysozyme was quantitatively adsorbed onto PBC. The adsorption capacity of PBC for lysozyme (MW 14,300) was higher than that of PPC. In contrast, PBC and PPC had similar adsorption capacities for tryptophan methyl ester (MW 219). From these results the chemically modified bacterial cellulose can be expected to adsorb large quantities of biomacromolecules.
\end{abstract}

Key words: bacterial cellulose, cellulose phosphate, adsorption, amine, protein

\section{Introduction}

Bacterial cellulose (BC) is an extracellular cellulose synthesized by some bacteria, such as Acetobacter xylinum [1, 2]. This BC is the raw material of "nata de coco", a traditional dessert food of the Philippines prepared from coconut water and sucrose. The molecular structure of $\mathrm{BC}$ is similar to that of higher plant cellulose (PC), however the fibrous structure of $\mathrm{BC}$ is quite different from that of $\mathrm{PC}$ : $\mathrm{BC}$ is composed of microfibrils, which have a ribbon-like structure, and the thickness of the microfibrous structure of $\mathrm{BC}\left(0.1 \times 10^{-6} \mathrm{~m}\right)$ is much less than that of $\mathrm{PC}\left(10 \times 10^{-6} \mathrm{~m}\right)$. On the basis of the microfibrous structure, $\mathrm{BC}$ shows advantageous properties such as high tensile strength, elasticity, and a large surface area. Therefore, various studies in which BC is used as a raw material for preparing advanced materials have been conducted [3]. For instance, Yano and coworkers recently developed optically-transparent composites reinforced with networks of BC [4]. Authors recently focused on $\mathrm{BC}$ as a raw material to prepare a new adsorbent $[5,6]$. Phosphorylated bacterial cellulose (PBC) was prepared as an adsorbent for transition metal ions and lanthanide metal ions. Quantitative adsorption of the transition metal ions and lanthanide metal ions were adsorbed onto PBC.

In the present study, adsorption of organic amines and a cationic protein, lysozyme, onto PBC have been studied. The physiologically important dopamine, adrenaline, noradrenaline, and serotonin exist as cationic species under acidic conditions and should therefore be adsorbed onto a cation exchanger. Furthermore, adsorption of such molecules onto chemically modified BC would be preferable because the microfibrous structure of PBC is well suited to binding and retaining biomacromolecules [7, 8]. Two modified celluloses were prepared, $\mathrm{PBC}$ and phosphorylated plant cellulose (PPC). Their adsorption behaviors were compared in order to understand the effects of fibrous structures on protein adsorption. 


\section{Experimental}

\subsection{Materials}

The starting material $\mathrm{BC}$ was prepared from "nata de coco" by grinding, washing with distilled water, and lyophilization. Cellulose powder as PC originating from a plant source was purchased from AdvantecToyo Kaisha, Ltd., Japan. The PBC was prepared from BC according to the procedure shown in scheme $1[5,6]$. After lyophilization and grinding, around $200 \mu \mathrm{m}$, PBC was obtained as white powder. The PPC was prepared from PC in a similar manner. A small amount of PBC or PPC was hydrolyzed with sulphuric acid and the concentration of phosphoric acid in the solution was analyzed with an ICP/AES spectrometer (Shimadzu ICPS-7100). This was to determine the degree of phosphorylation of the cellulose phosphates per monomer glucose unit. Preparations of PBC and PPC were examined several times under various conditions. Lysozyme from egg white was purchased from Nacalai Tesque Inc. and used without further purification. All other reagents were of reagent grade and were used as received.

Scheme 1 Synthetic route of phosphorylated bacterial cellulose (PBC)

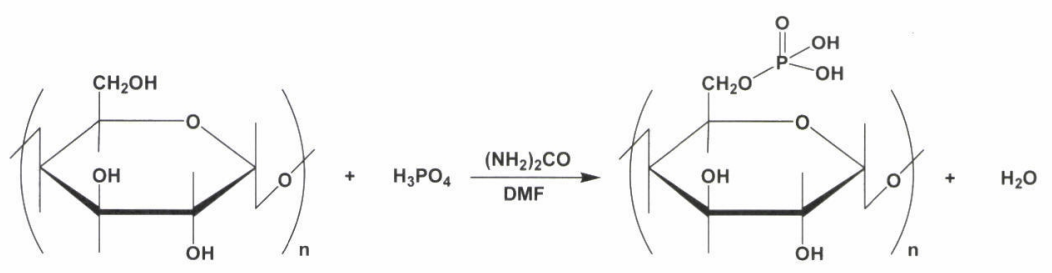

\subsection{Adsorption Tests}

Adsorption experiments for organic amines and lysozyme were carried out in a batchwise method as follows. An aqueous solution was prepared by dissolving $0.2 \mathrm{mmol} / \mathrm{dm}^{3}$ of organic amine (adrenaline, noradrenaline, dopamine, serotonin, or tryptophan methyl ester) as hydrochloride, or $0.2 \mathrm{mmol} / \mathrm{dm}^{3}$ of tryptophan into $100 \mathrm{mmol} / \mathrm{dm}^{3}$ glycine- $\mathrm{HCl}$ buffer solution. A portion $\left(15 \mathrm{~cm}^{3}\right)$ of the aqueous solution and adsorbent (20mg) were mixed in a stoppered glass tube and vigorously shaken in a thermostat-regulated shaker at $30^{\circ} \mathrm{C}$. After 24 hours the adsorption had reached equilibrium state and the mixture was filtered. The concentrations of the corresponding amines in the aqueous solution were determined by a UV-VIS spectrophotometer (JASCO U-best v560) to determine percentage of the adsorption (\%Ads [-]) and amount of the adsorption (q [mmol/g]). Adsorption of lysozyme was also examined in the similar manner, using a portion $\left(15 \mathrm{~cm}^{3}\right)$ of an aqueous solution containing $10 \mu \mathrm{mol} / \mathrm{dm}^{3}$ of lysozyme and $10 \mathrm{mg}$ of the adsorbent.

\section{Results and Discussion}

\subsection{Characteristics of Cellulose Adsorbents}
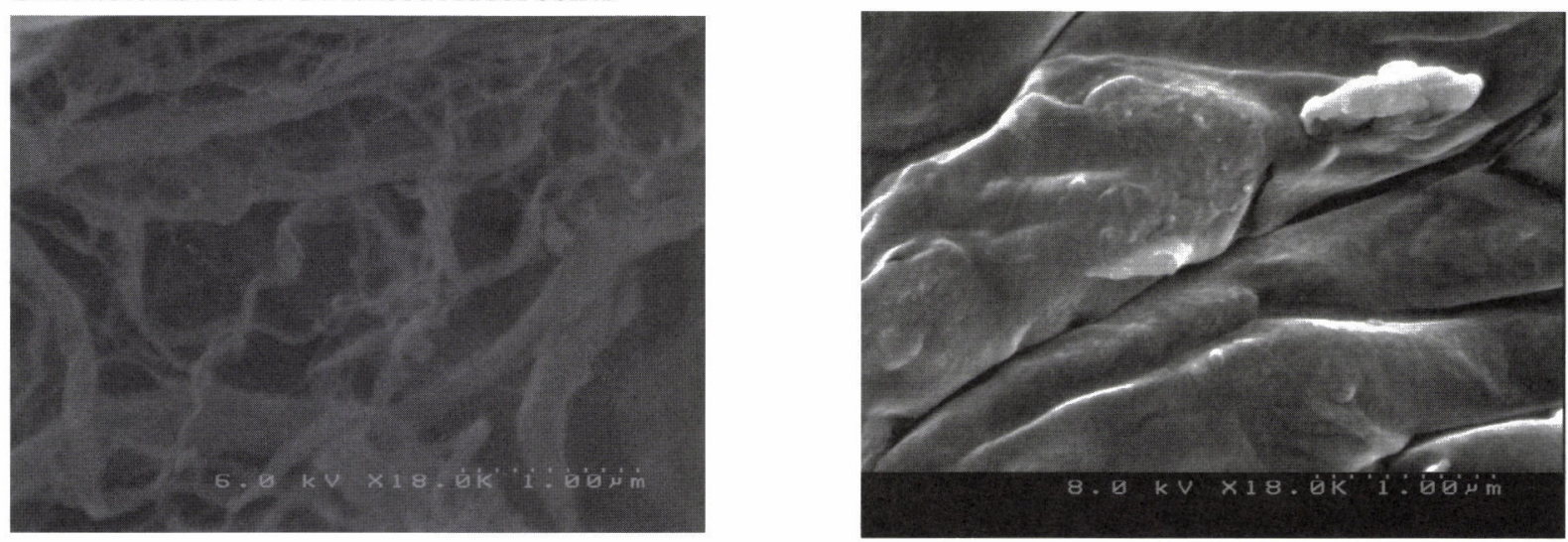

Fig.1 Scanning electron micrograph of PBC (left) and PPC (right) at × 18,000 magnification. 
The scanning electron micrographs of $\mathrm{PBC}$ and $\mathrm{PBC}$ are shown in Fig. 1. As shown in the photograph, the microfibrous ribbon structure can be observed on the surface of $\mathrm{PBC}$, which is quite different from that of PPC from plant cellulose. The ribbons of $\mathrm{PBC}$ are approximately $0.1 \mu \mathrm{m}$ thick. The microfibrous structure of $\mathrm{BC}$ is retained through the phosphorylation procedure.

\subsection{Adsorption of Organic Amines onto PBC}

Adsorption profiles of organic amines onto $\mathrm{PBC}$ at a range of different pHs are shown in Figure 2, as well as an adsorption profile of dopamine onto BC. Except for tryptophan, the amino compounds exist as cationic species under the acidic conditions examined. The organic amines adrenaline, noradrenaline, dopamine, serotonin, and tryptophan methyl ester were adsorbed onto $\mathrm{PBC}$ when the $\mathrm{pH}$ exceeds 4 . As the organic amines such as dopamine are adsorbed onto PBC through electrostatic interaction,

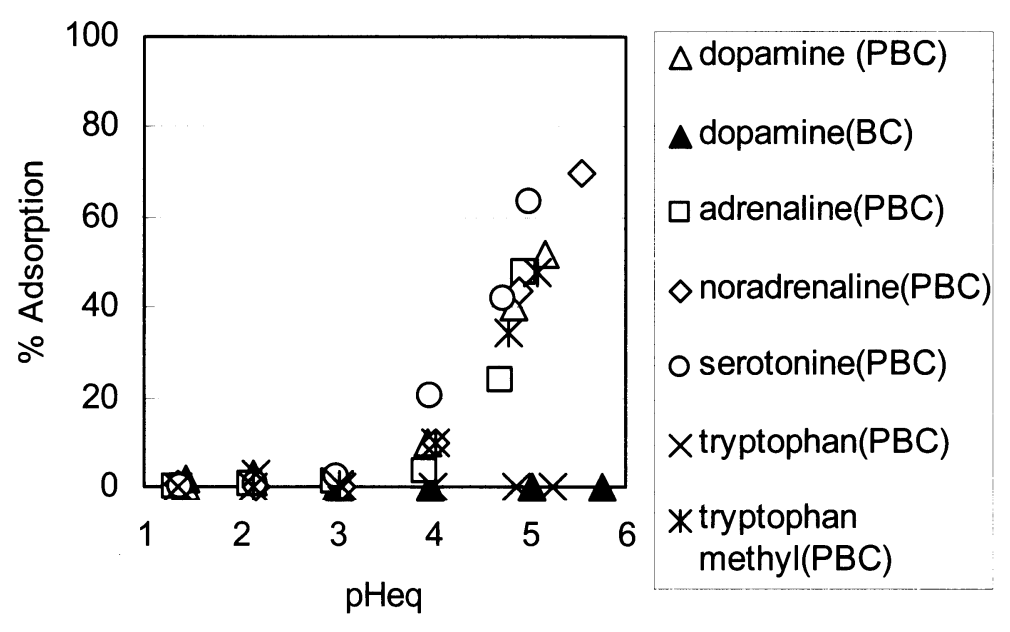

Fig. 2 Adsorption profiles of organic amines onto $\mathrm{PBC}$ and $\mathrm{BC}$ : adsorbent (PBC (phosphorylation degree: 3.1\%) or BC); 20mg, volume; $15 \mathrm{~cm}^{3}$, [amine $]_{\text {ini }}=0.2 \mathrm{mmol} / \mathrm{dm}^{3}$, media; $100 \mathrm{mmol} / \mathrm{dm}^{3}$ glycine- $\mathrm{HCl}([\mathrm{NaCl}]=0)$. dopamine is not adsorbed onto the starting material BC. On the other hand, the hydrophobicity of the amines does not relate to adsorption because the cellulose adsorbent is a hydrophilic material. The zwitterionic amino acid tryptophan was not adsorbed onto PBC at all under acidic conditions.

Furthermore, the effect of the concentration of inorganic salt in the solution for adsorption of the amines was investigated (data not shown). Tryptophan methyl ester was not adsorbed at all in the presence of 20 $\mathrm{mmol} / \mathrm{dm}^{3}$ of $\mathrm{NaCl}$ (100 times equivalent to tryptophan methyl ester), due to the interference from $\mathrm{Na}^{+}$.

\subsection{Adsorption of Lysozyme onto PBC}

The $\mathrm{pH}$ dependence for adsorption of lysozyme (MW 14,300, pI 11.1) is shown in Fig. 3. The adsorption of lysozyme onto PBC was increased as the aqueous $\mathrm{pH}$ decreased to lower than the $\mathrm{pI}$, under which lysozyme exists as cationic species. As such, lysozyme was quantitatively adsorbed onto $\mathrm{PBC}$ at $\mathrm{pHs}$ less than 6. In contrast, $\mathrm{BC}$ did not adsorb the protein at all under all $\mathrm{pHs}$ examined. On the basis of these results, the protein is adsorbed onto PBC through electrostatic interactions.

Figure 4 shows adsorption isotherms of lysozyme onto the cellulose phosphates PBC and PPC at varying equilibrium concentrations, as well as those

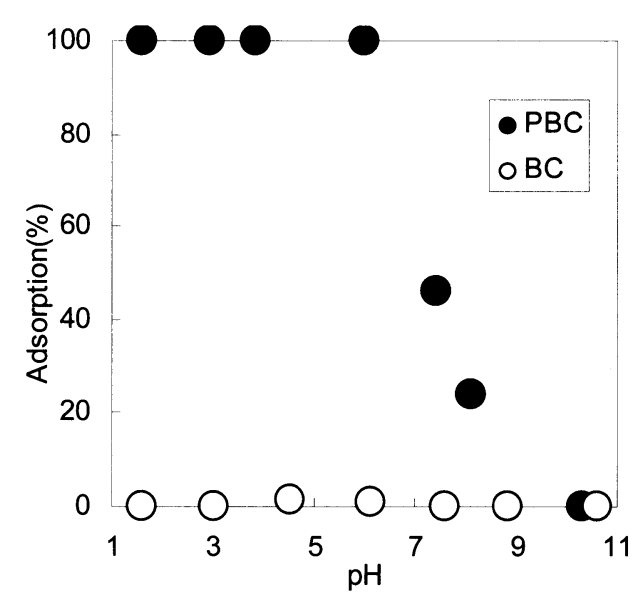

Fig. 3 Adsorption profiles of lysozyme onto PBC and $\mathrm{BC}$ : adsorbent; $10 \mathrm{mg}$, volume; $15 \mathrm{~cm}^{3}$, $\left[\right.$ lysozyme $_{\mathrm{ini}}=10 \mu \mathrm{mol} / \mathrm{dm}^{3}$. 
onto the celluloses $\mathrm{BC}$ and PC. The phosphorylation degrees of adsorbents used in this experiment were $2.4 \%$ for $\mathrm{PBC}$ and $2.8 \%$ for PPC. As shown in Fig. 4, lysozyme was adsorbed similarly onto cellulose phosphates $\mathrm{PBC}$ and PPC, but not onto $\mathrm{BC}$ and PC. The amounts of adsorption onto PBC and PPC approach constant values. The theoretical curves of adsorption isotherms for PPC and $\mathrm{PBC}$, from the Langmuir isotherm model, were depicted in the figure. The $\mathrm{q}_{\max }$ values of lysozyme were $28.1[\mu \mathrm{mol} / \mathrm{g}]$ for $\mathrm{PBC}$ and 11.7 $\left[\mu \mathrm{mol} / \mathrm{g}\right.$ ] for PPC. It should be noted that $\mathrm{q}_{\max }$ value of lysozyme onto $\mathrm{PBC}$ is much larger than that onto PPC; nonetheless the phosphorylation degree of $\mathrm{PBC}$ is less than that of PPC.

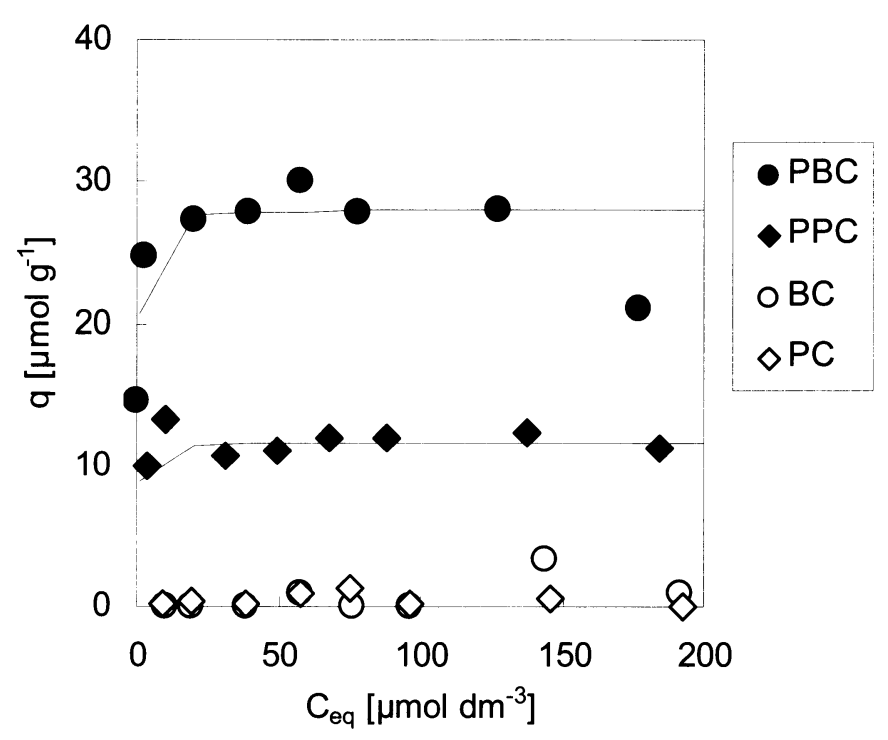

Fig. 4 Adsorption isotherms of lysozyme onto PBC, PPC, $\mathrm{BC}$, and $\mathrm{PC}$ at $30^{\circ} \mathrm{C}: \mathrm{pH}_{\text {ini }} 3.0$, adsorbent; $10 \mathrm{mg}$, volume; $15 \mathrm{~cm}^{3}$, [lysozyme $]_{\mathrm{ini}}=10-200 \mu \mathrm{mol} / \mathrm{dm}^{3}$.

In contrast, the $\mathrm{q}_{\max }$ values of tryptophan methyl ester onto $\mathrm{PBC}$ (phosphorylation degree $=3.6 \%$ ) and PPC (phosphorylation degree $=3.1 \%$ ) were similar; $0.52[\mathrm{mmol} / \mathrm{g}]$ for PBC and $0.51[\mathrm{mmol} / \mathrm{g}]$ for PPC. Ougiya and coworkers reported that bacterial cellulose exhibits larger adsorption capacity for cellobiose dehydrogenase compared to wood pulp cellulose [8]. Similarly, our own findings are that the chemically modified bacterial cellulose, which has a microfibrous structure, exhibited large adsorption capacity of biomacromolecules compared to the chemically modified plant cellulose.

\section{Acknowledgement}

This work was partly financed by the Cooperation for Innovative Technology and Advanced Research in Evolutional Area from the Ministry of Education, Science, Sports and Culture of Japan.

\section{References}

1) E. J. Vandamme, S. De Baets, and A. Steinbuchel, Biopolymers: Polysaccharides I: Polysaccharides from Prokaryotes, WILEY-VCH (2003), Chap. 3, pp.40-90.

2) M. Iguchi, S. Yamanaka, and A. Budhiono, J. Mater. Sci., 35, 261-270 (2000).

3) B. R. Evans, H. M. O'Neill, V. P. Malyvanh, I. Lee, and J. Woodward, Biosens. Bioelectron., 18, 917-923 (2003).

4) H. Yano, J. Sugiyama, A.N. Nakagaito, M. Nogi, T. Matsuura, M. Hikita, and K. Handa, Adv. Mater., 17, 153-155 (2005).

5) T. Oshima, K. Kondo, K. Ohto, and K. Inoue, Proceeding of International Solvent Extraction Conference (ISEC2005), pp.846-851, (2005).

6) T. Oshima, K. Kondo, K. Ohto, K. Inoue, and Y. Baba, Submitting to React. Funct. Polym. (2007).

7) M. Tabuchi and Y. Baba, Anal.Chem., 77, 7090-7093 (2005).

8) H. Ougiya, N. Hioki, K. Watanabe, Y. Morinaga, F. Yoshinaga, and M. Samejima, Biosci. Biotechnol. Biochem., 62, 1880-1884 (1998). 